\title{
Exclusion: The Necessary Difference between Ideal and Practical Consensus
}

\author{
STEPHEN CONNELLY \& TIM RICHARDSON
}

Department of Town and Regional Planning, University of Sheffield, Sheffield, UK

(Received September 2002; revised October 2003)

\begin{abstract}
Consensus building has become an everyday activity in environmental planning and management, and its use is often held to be a symbol of a fair, transparent and fully participative process. However, this paper argues that in any real situation practical constraints and tensions between different goals lead almost inevitably to compromises in the ideals of inclusivity and non-coercion. This gap between ideal and practical consensus is opened by a range of practices which exclude potential participants, interests, issues, actions and/or substantive outcomes. The paper contends that insufficient attention is paid by practitioners and researchers to these shifts, which are often confused or masked by a rhetoric of ideal consensus. It is concluded that practitioners need to reflect critically on these questions of exclusion, so that the necessary but difficult judgements involved in designing practical consensus building processes can be made transparently, and in ways which do not undermine the processes' legitimacy.
\end{abstract}

\section{Introduction}

Decision-making processes based on consensus building are increasingly regarded as a useful approach when dealing with existing or anticipated conflicts over environmental planning and management. Emerging from and embodying broader shifts in attitudes and forms of governance, citizens and other stakeholders now routinely engage with the traditional institutions of government through a proliferation of innovative forms of public involvement and partnership structures. Consensual approaches have been promoted in particular for developing strategic plans and managing local areas or sites where complex environmental and social issues are being dealt with, and where many divergent interests are likely to be affected by policy decisions. Attempts to establish consensus are frequently made where more traditional approaches to decision making have been obstructed by apparently insurmountable conflicts between different interests. Although it is sometimes assumed that simply bringing different interest groups together as 'partners' will result in consensual decision

Correspondence Addresses: Stephen Connelly and Tim Richardson, Department of Town and Regional Planning, University of Sheffield, Sheffield S10 2TN, UK. Email: s.connelly@sheffield.ac.uk; tim.richardson@sheffield.ac.uk 
making, increasing attention is being paid to how processes and structures can be explicitly designed to encourage the development of consensus.

Such 'consensus building' is usually presented as the search for an ideal outcome: an agreement subscribed to by all stakeholders and arrived at through an open, participative and non-coercive process which delivers legitimacy, respect, authenticity (in the sense that everyone's views can be expressed, heard and understood) and transparency (O'Riordan \& Ward, 1997). However, in practice the outcomes may include a greater exposure of conflicts and differences of interest and outputs which are either bland vision statements unaccompanied by prescriptions for action (Scott, 1999) or which lack legitimacy amongst those not directly involved (O'Riordan \& Ward, 1997).

This paper contends that these difficulties are not coincidental. Consensus rarely, if ever, emerges unproblematically since in any real situation practical constraints and tensions between different goals lead almost inevitably to compromising the ideals of inclusivity and non-coercion. These inevitable steps away from ideal consensus towards a more practical consensus involve a series of critical decisions which necessarily lead to the exclusion of some of the potential participants, interests, issues, actions and/or substantive outcomes. However, such compromises are often confused or marked by a rhetoric of ideal consensus. This is clearly problematic, since such (mis)representations break the principle of transparency and so threaten the legitimacy of a process.

The intention of this paper is to address these issues by opening up for inspection the differences between consensus building in theory and in practice. The next section sets out what consensus building is, locates it in relation to the associated ideas of public involvement and partnership, and the broader social and political currents which have brought it to the fore, and indicates when and why it is considered to be an appropriate approach to environmental management. An analysis is then presented showing how practice can stray from the ideal of inclusiveness along differing dimensions of exclusion. Using these ideas, the paper finally identifies a series of key questions for practitioners and researchers, which bring to the surface the exclusionary choices faced in practice, focusing attention on the crucial phase of design before a process starts in earnest.

It must be emphasized that no attempt is being made here to adopt a position 'for' or 'against' consensus building. Instead, the intention is to encourage a critical analysis of, and debate over, its nature and effectiveness, and a more reflective approach in considering whether and how to use a consensus building approach in particular rural development and planning situations. When consensus building is adopted, it is argued that in the interests of achieving effective solutions which have the legitimacy to command widespread support, process design should be conscious and accountable, with due consideration of its implications and rationales.

\section{Consensus Building: Between Participation and Partnership}

Consensus building is essentially an approach to decision making, and while approaches vary they share certain distinctive characteristics compared with non-consensual decision making. Sidaway (1998) identifies three specific distinctions: that decisions are reached through mutual consent (rather than, say, voting) with each participant given the power of veto; that everyone with an 
interest and who is prepared to co-operate participates in the process; and that a deliberative process is constructed based on principles of fairness, openness and trust. While outcomes which yield benefits to all participants are also a distinguishing characteristic (Sidaway, 1998), the quality of the process is equally important. In practice, not all consensus building processes make their working principles so explicit, or even consciously focus on process norms and design considerations.

In policy literature, consensus building is often associated with two distinct styles of current policy making, one based on public involvement, the other based on partnership working between agencies. Looking first at consensus building as an approach to public involvement, in perhaps the most widely used typology, public participation ranges from state control and informing the public through to citizen control of budgets and policy making (Arnstein, 1969). Here, consensus building involving state and public actors "represents a move up the ladder of public participation from information provision and formal consultation to proactive involvement in influencing decisions" (Petts, 1995, p. 521) and is situated on the middle rungs, elsewhere described by Wilcox as "deciding and acting together" (Wilcox, 1994). While it can draw on many of the tools which have been developed for increasing public participation in decision making (e.g. visioning techniques, environment fora, round tables, and citizens' juries (Williams, 1995; Young, 1996)) it should be seen as an approach to public participation rather than just as a method. It is its norms and rationales which are distinctive, rather than the practical methods adopted, and these are associated with the entire policy process, rather than simply with the public's participation.

However consensus building also frequently takes place between agencies operating in a more exclusive partnership setting not involving the public. Here 'partnership' can be understood as:

organizations coming together for 'collaborative advantage' (Huxham, 1993) - to achieve an objective that no single organization could achieve alone. (Wilson \& Charlton, 1997, p. 10)

Such partnerships often pursue consensuality in their ways of working, as it "helps to increase perceptions of equality of status internally and fair representation externally" (Wilson \& Charlton, 1997, p. 5).

So consensus building should be understood as more than simply a method of public participation, and more than an element of partnership working. Consensus building processes can contain elements of both participation and partnership, so blurring the boundaries between the two. Its distinguishing characteristic in both cases is its approach to decision making: the norms of common goals, absence of coercion, and inclusion of all relevant stakeholders, whether they be members of the public, civil society groups or business or state sector organizations. Consensus building processes may thus include widely divergent constellations of actors of different types.

\section{Origins of Consensus Building}

The current emphasis on consensual approaches has emerged from two changes in approaches to governance, the first towards more inclusionary governance, the second towards increased partnership working. 
The inclusionary turn reflects two potentially contradictory shifts in broad social attitudes towards the appropriate relationship between state and citizen. On the one hand there is a turn towards more participative democracy and less willingness to trust the representative democratic system, and at the same time there is increasing differentiation of identities and of demands (Healey, 1990). These shifts are embodied in currently dominant policy agendas. Thus a central element of the government's vision of successfully modernized local government in England is councils engaging directly with their local communities, and taking a lead role in 'local strategic partnerships' established to prepare community strategies which reflect a shared vision of 'the community's' interest (Department of the Environment Transport and the Regions, 1998; 2001). Further, it is widely accepted that consensual decision making processes are integral to advancing sustainable development (UNCED, 1992; Leach et al., 2000) and that bringing citizens more actively into governance will both recreate a sense of community and rebuild the relationship between people and state (e.g. Commission of the European Communities, 1992).

This is underpinned by an ideological shift towards assuming that consensus working (constructed as an avoidance of conflict) is the best way to resolve difficult policy challenges, an idea made explicit, for example, in New Labour's Third Way discourse in Britain (Fairclough, 2000; Rydin \& Thornley, 2002). A powerful discourse of consensuality has been institutionalized in the promotion of consensus building processes at the expense of traditional forms of representative democracy, particularly at the local level. There has, of course, been an increasing emphasis on public involvement in local government, and particularly planning, for more than 30 years, but recent developments are arguably part of a broader shift in dominant assumptions about policy making. Traditional forms of public involvement have increasingly been criticized both for denying the public any real influence over decision making (Renn, 1998; Booth \& Richardson, 2001) and for promoting (unhelpful) conflict rather than consensual progress (Petts, 1995). Moreover, whereas a long-standing normative distinction exists between 'bottom-up' (good) and 'top-down' (bad) approaches (Young, 1996) new, consensual approaches to public involvement are claimed to blur this distinction (Selman, 1998) and embody a new ideal-the goal is no longer the top of the ladder but the middle rungs where state and citizen make decisions together.

Concurrent with this shift towards more inclusive governance has been the growing dominance of partnership working between agencies. This has arisen as a corollary to the dispersal of authority away from traditional government structures to create a more fragmented system of governance (Rhodes, 1997), and the resulting need to co-ordinate policies and programmes lying within the remit of separate, independent agencies (Lowndes \& Skelcher, 1998).

The inclusionary turn and the increase in partnership working have converged to create a new environment where partnerships of stakeholders from all sectors of society have become the ideal model of governance (Department of the Environment Transport and the Regions, 1998; 2001). In practice this results in myriad hybrid institutional forms which break down the distinction between 'public participation' as involving the state and the public as two separate players, and 'partnerships' as groupings of state agencies. While usually based on consensus principles, increasing use is being made of explicit consensus building processes in these structures. 
However, the new consensual wave runs alongside the still-powerful processes of traditional representative democracy, creating complex overlaps and engagements. A full analysis of a consensus building process in a public policy context would therefore need to pay attention to the crucial issue of linkage between it and representative structures, as well as to other stakeholder-based processes, in order to identify where effective decision making actually takes place. This paper addresses this to the extent that such linkage is a function of the design of a process, while it is recognized that other factors also play a part in determining its effectiveness (Sharp \& Connelly, 2001; Owens \& Cowell, 2002).

\section{Uses and Rationales for Consensus Building in Environmental Planning and Management}

Within the field of environmental management and planning the presumption in favour of seeking consensus is manifested in an increasingly varied range of practical applications of consensus building. These are claimed to be useful in a wide range of problematic decision-making situations, which fall into two broad categories of dealing with conflict and complexity (see Table 1).

The first makes use of consensus building as a particular approach to conflict resolution, characterized by its voluntary nature and its emphasis on negotiation and mediation, in contrast with methods involving compulsion through arbitration, litigation or enforced mediation (Sidaway, 1998). This category includes single issue cases, such as siting controversies, where there is conflict between those supporting and opposing development, or in cases of policy breakdown (Petts, 1995). The second category is where consensus building is used in areas where complex environmental and/or social issues involving many divergent interests have to be addressed. In such cases, there are both democratic grounds and conflict avoidance grounds for explicitly addressing the complexity, and for ensuring that all interests are reflected in the decisionmaking process. Specific applications include many different cases of complex area management planning, and community based natural resource management, as well as community planning. It should be noted that these are not hard and fast distinctions. The need for complex area management often arises out of specific problem solving or conflict resolution episodes, while consensus building processes can in themselves lead to future conflicts.

\section{Ideal and Practical Consensus}

The claims for the utility of consensus building rest on a number of different rationales. Drawing on Healey's (1997) work on collaborative planning, a range of possibilities are identified (Table 2). Clarity is important about which of these rationales actually underpin the process in any given situation, since they have potentially conflicting implications for the design of consensus building processes. This leads to a consideration of the important and necessary distinction between 'ideal consensus' and 'practical consensus' and the analysis of the different ways in which practice departs from the ideal.

The ideal consensus building process delivers a freely reached agreement between all parties with an interest in the issue, to which they all subscribe and from which they all gain. However, where consensus building is used to address 
Table 1. Applications of consensus building

\begin{tabular}{ll}
\hline Conflict resolution & Complex management \\
\hline - Complex area management with known & - Complex area management planning, e.g. \\
conflicts, e.g. access vs. conservation, & national parks, estuaries, catchments, nature \\
conservation vs. hunting, farming vs. & reserves, forests (e.g. Margerum \& Born, 1995; \\
wildlife (e.g. Warner \& Jones, 1998). & Edwards-Jones, 1997; Scottish Natural \\
- Breakdown in specific policies (e.g. Petts, & Heritage, 1999; Roe, 2000; Wragg, 2000). \\
1995). & - Community planning (typically urban \\
- Controversial single site decisions (e.g. & settings) (e.g. Hastings et al., 1996; Illsley \& \\
Petts, 1995). & McCarthy, 1998). \\
& - Integrated sustainable development planning, \\
& LA21 (e.g. Scott, 1999). \\
& Community based natural resource \\
& management (e.g. Inglis \& Guy, 1996; Forest \\
& Enterprise, undated). \\
\hline
\end{tabular}

difficult complex and/or contested issues, this is obviously a hard or even impossible ideal to attain, given the differing goals, interests, expectations and levels of trust in each other held by different potential participants, frequently compounded by initial attitudes or histories of antagonism. Furthermore, available resources are inevitably limited and often insufficient.

The unforced nature of an ideal consensus building process can also be compromised for other reasons. The simple framing of a process as having consensus as its aim affects its nature (Hooghe \& Marks, 2001) engendering a pressure towards consensus making rather than building, as participants compromise in order to reach an agreement in situations more akin to bargaining and compromise than ideal consensus. In such processes either the status quo may be the natural outcome (Blowers, 1980) or the outcome may gravitate towards the interests of those forcing the agenda.

Such effects blur with more self-interested actions, in that actors may have goals beyond the immediate issues which incline them towards maintaining the

Table 2. Alternative rationales for consensus building

Instrumental

- Building support for decisions, and in particular overcoming known differences over what a decision should be.

- Bringing in more expertise and knowledge, in particular bringing in lay knowledge to complement expert knowledge.

Political and Social

- Consensus building as an arena for working through and overcoming ideological and political differences.

- Building social capital, on the assumption that the process itself develops relations of trust and new linkages between participants (Amdam, 2000).

Normative and ethical

- People have a democratic right to be involved in decisions that affect them.

Source: adapted from Healey, 1997. 
process, in order to, for example, sustain links with other participants, or simply to use the process strategically to achieve their own goals.

Therefore, a number of tendencies and temptations exist which moderate the form of consensus which is aimed at or achieved to something less than the ideal. These are made effective through the choices and decisions made by those initiating, designing and managing a process. That this phase is important and confers a significant amount of power on the designers is widely recognized (e.g. Alterman, 1982; Wilcox, 1994) but is usually presented as unproblematic, merely a matter of administration, rather than as a crucial element determining the outcomes and legitimacy of a process.

The choices that are made can compromise the ideal of inclusivity along any or all of three dimensions:

- exclusion of people;

- exclusion of issues; and

- exclusion of outcomes.

\section{Exclusion of People}

Sidaway's (1998) definition implies that the ideal form of consensus building is a broad based participative approach open to all stakeholders, defined as those sharing risks, costs and benefits (Abbott, 1996), and having "the right to participate in the decision-making process" (Clarke, 1996). Such descriptions are problematic, since in some cases (e.g. major environmental issues) they arguably give everyone a right of involvement, and in many cases encompass practically unreachable numbers of people. Practical consensus building therefore usually requires a limited selection of stakeholders to be either identified or invited to participate, and so, conversely, a choice of who to exclude. This raises three interrelated issues - the 'location' of consensus, the choice of potentially affected people, and the relationships between those 'inside' and 'outside' the process.

A useful way of analyzing the exclusion of stakeholders is by considering the 'location of consensus'. If the possible participants are characterized as citizens, representative groups and agencies then different patterns of participation can be identified depending on these decisions. Figure 1 shows the consensus building ideal where all interests and stakeholders are fully and unproblematically involved in the process. In practice, however, consensus is more normally developed and located within more restricted groups. This process can take a number of forms, set out here and mapped out in Figure 2 in relation to the ideal:

- Closed/partnership: the consensus includes agencies and representative groups from across the categories, but is limited to an exclusive subset of potential stakeholders;

- Agency based partnership: consensus is developed within a local authority or small group of agencies, often following consultation with other stakeholders;

- Representative group based: a consensus is genuinely built between different representative groups, but does not include policy-making agencies and so is ineffective;

- Citizen based: similar to consensus built between representative groups, but open to participation by individual citizens. 


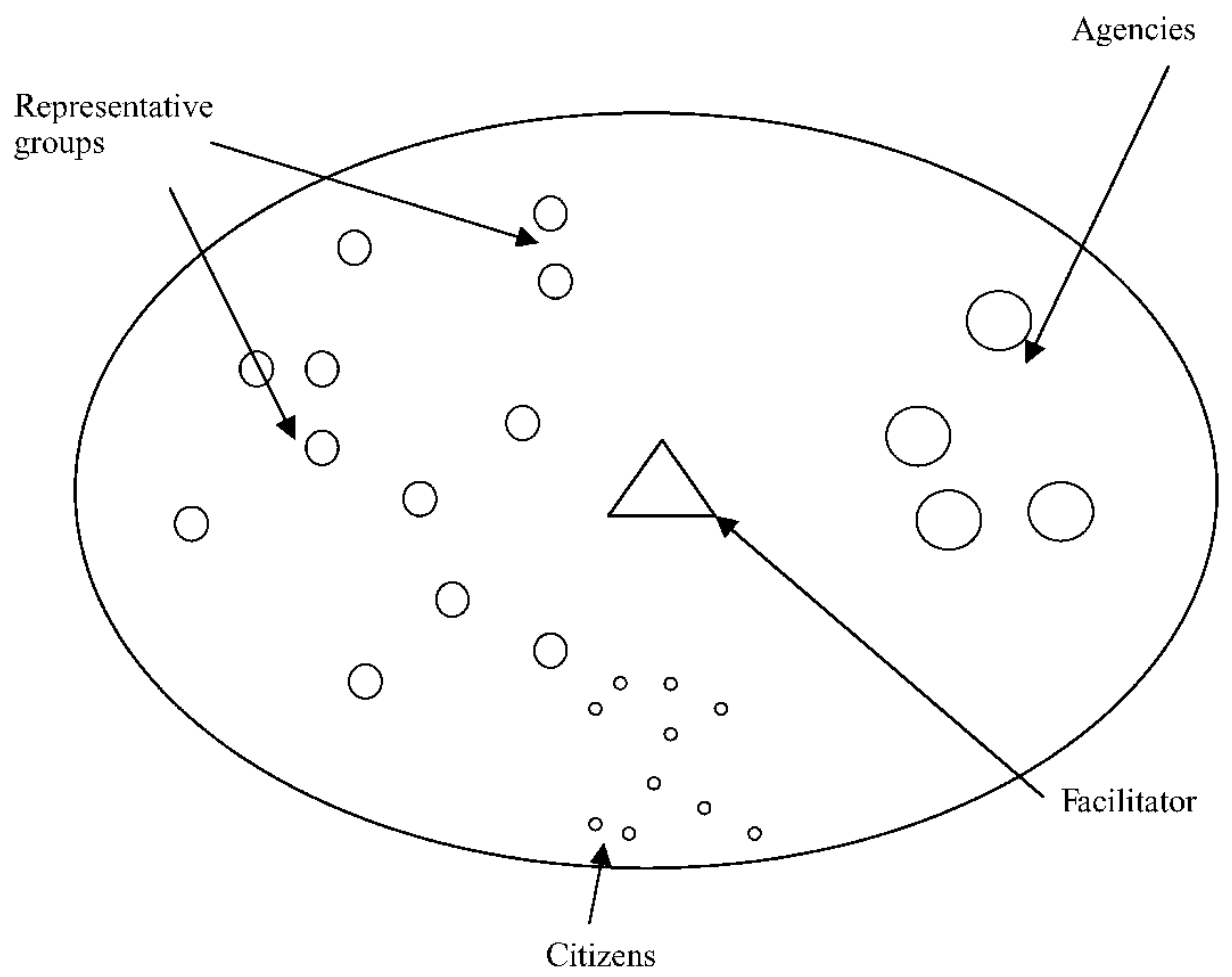

Figure 1. Ideal model of consensus building.

These different potential locations for consensus imply qualitatively very different applications of consensus building, each with different rationales. Closed processes tend to be based on an instrumental rationale of pursuing efficiency. Representative- and citizen-based processes can contribute to building social capital, but are structurally restricted in their effectiveness in terms of affecting policies, and so in contributing to democratic goals. More open processes can encompass a wide range of rationales-they can be instrumental, in that in conflict-prone situations it may be necessary to involve people to make solutions stick-but they may well also embody the procedural rationale of pursuing democracy for its own sake, or broader social aims. However, very inclusive approaches risk diluting the focus and cohesion of the process, resulting in both ineffectiveness and loss of legitimacy and support if they degenerate into 'talking shops' (Wilson \& Charlton, 1997). Arriving at one of these structures necessarily involves hard decisions which define the inclusivity of the process, decisions which open up the opportunity for deliberate exclusion of stakeholders in order to further the process designers' substantive agendas, or simply to achieve the procedural aim of reaching a consensus through limiting overall numbers and excluding potential participants with known 'difficult' views.

The latter raises the issue of the potential conflict between instrumental aims and democratic and long term social goals. However, the need for legitimacy also makes these mutually dependent, a successful process needs to be both effective and command support. A balance must always be struck, between 


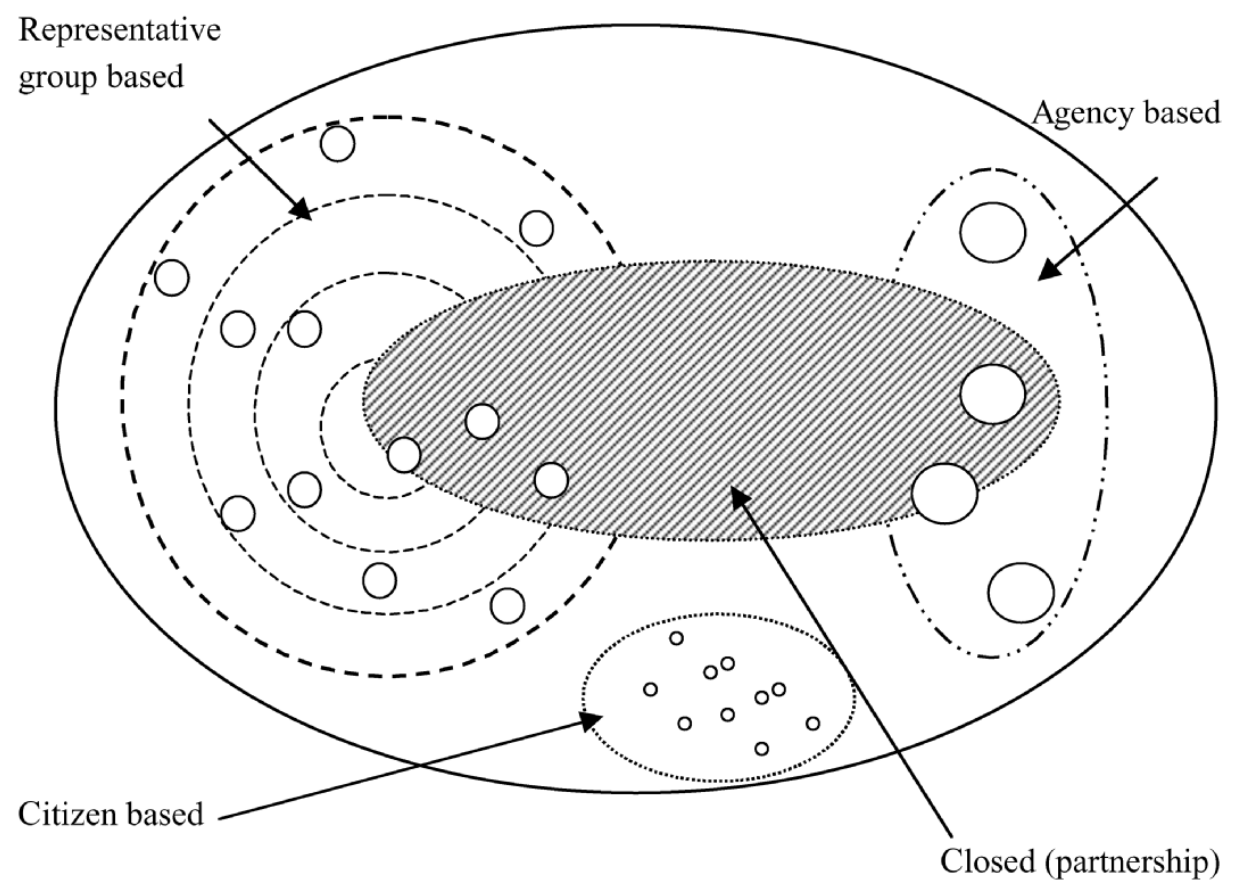

Figure 2. Possibilities for practical consensus.

selection of participants as a pragmatic decision based on who needs to be present to legitimize or make implementable any outcome, or based on democratic values that involvement should, in principle, be open to all.

Even when manipulation is not intended, identifying appropriate stakeholders is difficult. While it may be fairly obvious which 'agencies' should be involved, there are problems selecting stakeholders from the wider population of citizens and representative groups. It is increasingly recognized that this population is composed of 'multiple, sometimes conflicting, communities, some of which are spatially defined, and some of which are interest based' (Carley, 1995) and which are flexible, contested, provisional and precariously-constructed (Massey, 1994; Shurmer-Smith and Hannam, 1994; Illsley \& McCarthy, 1998). Despite this, consensus building practice still tends to assume that 'communities' are homogeneous and place-based, and/or to work with familiar representative groups. Both approaches can be unproductive and exclusionary (Bouriaud, 1999; Shucksmith, 2000). A notable exception has been in the field of participatory appraisal in the south, characterized by explicit attempts to seek out the views of those normally excluded in routine consultation (Chambers, 1983; 1997). However, this approach has been criticized for its blindness to power and manipulation even within its apparently inclusive practices (White, 1996; Cleaver, 2001; Cooke \& Kothari, 2001), and much of the present discussion is equally relevant to that field.

It is also clear that the selection of participants is not entirely under the control of process initiators. Despite the assumptions often made by policy makers, involvement of 'the public' and other stakeholders cannot be taken for granted. While non-involvement is often (pejoratively) ascribed to 'apathy', 
more perceptive observers have noted the occurrence of 'consultation fatigue' (Duncan \& Thomas, 2000) and the possibility that the intended participants may very rationally consider the potential benefits of involvement not to be worth the effort (Rydin \& Pennington, 2000). This is likely to be exacerbated by the widespread lack of trust of state institutions and the associated sense that participation is unlikely to affect policy, shared by individuals and groups from the voluntary and community sector (Macnaghten et al., 1995; Wilson \& Charlton, 1997; Duncan \& Thomas, 2000). The question then becomes whether consensus building processes can be part of (re)building that trust and sense of agency, implying in turn that processes need to be consciously designed with long-term goals of building social capital (Macnaghten et al., 1995; Amdam, 2000).

These difficulties associated with the selection of participants are inevitable. The tensions are often resolved through a combination of restricted consensus building supplemented with a process of consultation to involve a wider population. Such an approach is often adopted unproblematically (e.g. Roe, 2000) and has been proposed as the ideal by Margerum \& Born (1995). Nevertheless, it is unlikely to be satisfactory. Problems of legitimacy arise where consensus building is intended to be, or is presented as, open and democratic but in practice is set up to be, or becomes, restricted and exclusive (O'Riordan \& Ward, 1997).

The implication is that if limited partnerships are essential on efficiency grounds they have to have built into them safeguards in terms of access and public involvement to maintain their legitimacy. This raises the issue of linkage, since if some stakeholders are not to participate directly they must be brought into the system in other ways. Gillespie et al. (2000) stress the importance of feedback as well as consultation, claiming that this enables stakeholders 'outside' to be involved and maintain ownership even when the work is done by a smaller group. This approach gives a great deal of power to facilitators and insiders, a potential problem which is perhaps avoided by O'Riordan \& Ward's proposal that the consensus building group should be fluid, composed of "informal networks of interested parties on a 'come and go' basis" (O'Riordan \& Ward, 1997, p. 266). This entails a continuous assessment by the partners of how open they are being, and a preparedness to act on failings which are identified.

An alternative approach is to rely on some form of representation. This is complex and raises issues which are beyond the scope of this paper, and it is clear that steps in this direction move away from the consensual ideal of direct stakeholder involvement.

\section{Exclusion of Issues}

Alongside the exclusion of people is the exclusion of issues through focusing attention on selected issues and areas where agreement is most likely. At the broadest level this reflects a choice between two very different 'styles' of consensus building which have not been clearly differentiated in the literature. Usefully labelled 'conflictual' and 'non-conflictual', these are characterized by differing formats and underpinning philosophies and assumptions. Both rest on the assumed possibility of agreement, and the construction of participants not as antagonists with different, fixed interests but as stakeholders who from the beginning recognize that they have a common interest, a stake in something in 
common (Healey, 1998). However, it would be naïve to assume that a common interest is shared from the start, more usually participants come with the expectation of maximizing their own interests, as they initially perceive them to be, and perhaps without the goal of reaching a consensus. A necessary corollary is therefore the assumption of a possibility of movement in positions. Such movement relies on the potential for learning, through the acquisition and sharing of information (Margerum \& Born, 1995), the overcoming of misunderstanding (Sidaway, 1998) and through the creation of new ideas (Healey, 1998).

The two approaches differ strongly, however, in their understanding of how such movement can be best attained. 'Conflictual' processes draw more or less explicitly on the Habermasian ideal of communicative rationality (Skollerhorn, 1998; Forester, 1999). They strive to create arenas for debate which come as close as possible to realizing this ideal, through such increasingly popular applications as citizens' juries and panels (Renn et al., 1984; Petts, 1995). Differences in initial positions are explicitly sought out and consensus is reached through a process of argumentation-in an ideal situation purely through the force of the better argument, and reflecting the development of opposing positions into shared viewpoints. Furthermore, different viewpoints and forms of knowledge must be equally valued, in order that genuinely good arguments will be recognized for what they are, and the participants will collectively come to agree on the 'best', i.e. most rational, solution (Healey, 1997; Kumar \& Paddison, 2000). In contrast 'non-conflictual' processes explicitly exclude initial differences from discussion. They focus instead on a search for areas of common interest and then seek to build shared visions, working typically towards some kind of agreed action plan. This approach offers the clear attraction of facilitating agreement on possible action rather than getting 'bogged down' in argument. However, by excluding important issues and the full expression of conflicting viewpoints, problems may be suppressed which can re-emerge later in the policy making or implementation process. Furthermore, critics suggest that there are inherent risks in avoiding conflict, arguing that the mutual learning and 'transformation' which is fundamental to changing initial positions may require conflict rather than an illusion of common ground (Driver \& Kravatsky, 2000).

This latter approach appears to be rapidly gaining ground in Britain, particularly in broad-based participative approaches to natural resource management. Its conceptual underpinnings are hazy as they clearly do not fit the Habermasian model and perhaps should rather be looked for in political theories that deal with consensus as a value at a society-wide level rather than with the generation of consensus within processes (see, pre-eminently, the work of Talcott Parsons (e.g. 1957)).

\section{Exclusion of Outcomes}

The third dimension of exclusion is exclusion of outcomes and actions, where instead of pressing for substantive action-oriented outcomes, processes lead towards and create pressure for acceptance of general statements which can be agreed by all. For example, Selman (1998) argues that in general as participation was broadened in attempts to reach consensus in Local Agenda 21 processes it became harder to reach agreement and blander outputs were delivered. 


\section{Conclusion}

Since the ideal inclusive process is difficult, if not impossible to achieve, it becomes important for practitioners and researchers alike to get better at recognizing and responding to the often-obscured effects of practices which institutionalize exclusion in consensus building processes. Key decisions in process design should be made consciously and transparently, as they necessarily involve choices (made consciously or unconsciously) to exclude people, interests, issues, actions and possible substantive outcomes. These different dimensions of exclusion can result in different possible forms for consensus building processes. Through exclusion, consensus may be located between very limited numbers of stakeholders drawn from across society, or confined to relations between representatives of government agencies, or be genuinely broad-based but isolated in a 'bubble' of consensuality from the arenas in which real decision making is done.

A great deal of power is wielded by the designers and initiators of a consensus building process. Although the importance of power relations within consensus building processes is increasingly recognized in the literature, and political scientists have for many years acknowledged the power of those controlling the agenda and effectiveness of a decision-making arena, it is stressed here that the design of a consensus building process is an expression of the power of the initiators, and that exclusion is at the heart of these particular power relations. It is stressed that this is not inherently 'bad', but that it is inherent in consensus building. In practice, exclusion is necessary if consensus is to be achieved. Since this results from actors' choices, issues of power and politics cannot be ignored, and 'wished away' in the name of consensuality. However, exclusion does clearly carry risks. While consensus building processes may create situations which rebalance power relations between actors and are arguably elements in the development of a more pluralistic and direct democracy, they also potentially create and reinforce non-accountable systems and raise concerns about the 'quangocracy' and the 'new managerialism' (Duffy \& Hutchinson, 1997, p. 359). The latter situation is perhaps the more likely, given that the dynamics of policy making, reinforced by normative pressure to arrive at a consensus, tend to lead towards exclusion as a 'natural' process and the blunting of consensus building's transformative potential. Such processes are, however, often cloaked in a rhetoric which implies that decisions are made in a way which delivers at least an approximation to the 'ideal consensus'.

This 'necessary exclusion' leads to a set of questions to be considered by those involved in making critical decisions about whether and how to introduce consensus building processes (Table 3). Taking seriously these questions about exclusion should challenge process designers, in the face of the current widespread presumption in favour of using such approaches, to reflect on whether consensus building is an appropriate and honest description of the engagement with stakeholders that is being planned. In the face of perceived insuperable differences between interests or the positions of different stakeholders, or if there is no commitment to the exploration of conflict and opposition in order for transformation to take place (Blowers, 1980; Driver \& Kravatsky, 2000), adversarial (e.g. quasi-judicial) processes, or reliance on the democratic legitimacy of elected representatives may in some circumstances be more appropriate than attempts to build consensus. 
Table 3. Key questions in the design of consensus building processes

Conflicting aims:

- What are the relative priorities of aims of inclusivity of participants; effective policy making; and long-term social/political goals?

- Will an explicit consensus building approach be adopted?

Exclusion:

- Which of the possible actors in the process are going to be parties to the consensus which is built?

- What kind of consensus building is being sought: broad based participative, narrow partnership, or a hybrid, and where will it be located?

- What will the relationships be between those 'inside' and 'outside' the process?

- What issues will be covered?

- What 'style' of consensus building will be adopted: conflictual or non-conflictual?

- What kind of outcomes will be sought: broad visions and/or action plans?

And finally:

- Have all these key 'design' decisions been explicitly and accountably addressed? (i.e. has designing the process met the principles of openness and transparency which should be hallmarks of the process itself?)

The issues raised by these questions are equally relevant to researchers, and can be used heuristically to guide critical analysis. But researchers, like practitioners, do have to notice the issues. This raises further questions about how researchers and evaluators handle issues of power and exclusion whilst observing, analyzing and evaluating consensus building practice. This is put forward here as an important contribution to broaden current perspectives about researching consensus building. The clear implication is the need to focus on exclusion in its various forms, and to scrutinize from this perspective what has really been achieved when consensus is claimed in a particular setting. Avoidance of questions about exclusion means that researchers are not fully able to understand how and whether the core principles of consensus building are being achieved in practice, which in turn hinders the ability of practitioners to be fully reflexive in the way they approach consensus building.

Thinking critically about exclusion in consensus building, and recognizing the shifts away from ideal consensus in a practical setting, is uncomfortable but necessary. It is clear that there exists no generic framework for consensus building which can be universally applied, but rather that consensus building approaches need to be developed specifically for their application, reflecting the nature of the issues being addressed, the type of output required, the range and nature of possible stakeholders and the tensions between them, and the different needs for democratic participation, debate and action. It is hoped that this paper will assist practitioners and others engaged in or analyzing such processes to be appropriately critical and aware of exclusion in consensus building, rather than maintaining or believing a rhetoric of ideal consensus where this is not justified in practice.

\section{References}

Abbott, J. (1996) Sharing The City: Community Participation in Urban Management (London: Earthscan). 
Alterman, R. (1982) Planning for public participation: the design of implementable strategies, Environment and Planning (B), 9(3), pp. 295-313.

Amdam, J. (2000) Confidence building in local planning and development, some experience from Norway, European Planning Studies, 8(5), pp. 581-600.

Arnstein, S. (1969) A ladder of citizen participation, Journal of the American Institute of Planners, 34, pp. 216-225.

Blowers, A. (1980) The Limits of Power: The Politics of Local Planning Policy (Oxford: Pergamon).

Booth, C. \& Richardson, T. (2001) Placing the public in integrated transport planning, Transport Policy, 8(2), pp. 141-149.

Bouriaud, L. (1999) Linking social needs and interests in regional forest planning: a case in France. Regional Forest Programmes: a participatory approach to support forest based regional development, in Proceedings of the Nordic Research Course on Regional Forest Strategies (Mekrijärvi, Finland: European Forest Institute).

Carley, M. (1995) A community participation strategy in urban regeneration, working paper (Edinburgh: Scottish Homes).

Chambers, R. (1983) Rural Development (Harlow: Longman).

Chambers, R. (1997) Whose Reality Counts? (London: Intermediate Technology Development Group).

Clarke, P. B. (1996) Deep Citizenship (London: Pluto Press).

Cleaver, F. (2001) Institutions, agencies and the limitations of participatory approaches to development, in: U. Kothari Participation: The New Tyranny? (London: Zed Books).

Commission of the European Communities (1992) Towards Sustainability: A European Community Programme of Policy and Action in Relation to the Environment and Sustainable Development. The EC Fifth Environmental Action Plan (Brussels: CEC).

Cooke, B. \& Kothari, U. (2001) The case for participation as tyranny, in: U. Kothari Participation: The New Tyranny? (London: Zed Books).

Department of the Environment Transport and the Regions (1998) Modernising Local Government: Local Democracy and Community Leadership (London: DETR).

Department of the Environment Transport and the Regions (2001) Local Strategic Partnerships: Government Guidance (London: DETR).

Driver, T. \& Kravatsky, A. (2000) Participatory learning and action or participatory acting? in: L. Greenwood Participatory Processes in the North, PLA Notes 38 (London: IIED).

Duffy, K. \& Hutchinson, J. (1997) Urban policy and the turn to community, Town Planning Review, 68(3), pp. 347-362.

Duncan, P. \& Thomas, S. (2000) Neighbourhood Regeneration: Resourcing Community Involvement (Bristol: The Policy Press).

Edwards-Jones, S. (1997) The River Valleys Project: a participatory approach to integrated catchment planning and management in Scotland, Journal of Environmental Planning and Management, 40(1), pp. 125-142.

Fairclough, N. (2000) New Labour, New Language? (London: Routledge).

Forest Enterprise (undated) Working with Communities in Scotland: Our Commitment (Edinburgh: Forestry Commission).

Forester, J. (1999) The Deliberative Practitioner (Cambridge, MA: MIT Press).

Gillespie, S., Telfer, M. \& Halhead, V. (2000) Sowing seeds of sustainability with Duthchas, in: L. Greenwood Participatory Processes in the North, PLA Notes 38 (London: IIED).

Hastings, A., McArthur, A. \& McGregor, A. (1996) Less than Equal? Community Organisations and Estate Regeneration Partnerships (Bristol: The Policy Press, in association with the Joseph Rowntree Foundation).

Healey, P. (1990) Places, people and policies, Town and Country Planning, 59(1), pp. 9-10.

Healey, P. (1997) Collaborative Planning: Shaping Places in Fragmented Societies (Basingstoke: Macmillan).

Healey, P. (1998) Building institutional capacity through collaborative approaches to urban planning, Environment and Planning (A), 30, pp. 1531-1546.

Hooghe, L. \& Marks, G. (2001) Multi-level Governance and European Integration (Lanham, MD: Rowman \& Littlefield).

Illsley, B. \& McCarthy, J. (1998) Community-led planning? The case of Dundee, Scottish Geographical Magazine, 114(2), pp. 103-108.

Inglis, A. \& Guy, S. (1996) Rural development forestry in Scotland: the struggle to bring international principles and best practices to the last bastion of British colonial forestry, in: RDFN Network Paper $20 b$ (London: ODI). 
Kumar, A. \& Paddison, R. (2000) Trust and collaborative planning theory: the case of the Scottish planning system, International Planning Studies, 5(2), pp. 205-223.

Leach, M., Mearns, R. \& Scoones, I. (2000) Consensus or conflict? Time for a reality check on community-based sustainable development, in: id21 Research Highlights (Falmer, Sussex: IDS).

Lowndes, V. \& Skelcher, C. (1998) The dynamics of multi-organisational partnerships: an analysis of changing modes of governance, Public Administration and Development, 76, pp. 313-333.

Macnaghten, P., Grove-White, R., Jacobs, M. \& Wynne, B. (1995) Public Perceptions and Sustainability in Lancashire (Preston: Lancashire County Council).

Margerum, R. D. \& Born, S. M. (1995) Integrated environmental management: moving from theory to practice, Journal of Environmental Planning and Management, 38(3), pp. 371-391.

Massey, D. (1994) Space, Place and Gender (Oxford: Blackwell).

O'Riordan, T. \& Ward, R. (1997) Building trust in shoreline management: creating participatory consultation in shoreline management plans, Land Use Policy, 14(4), pp. 257-276.

Owens, S. \& Cowell, R. (2002) Land and Limits: Interpreting Sustainability in the Planning Process (London: Routledge).

Parsons, T. (1957) The distribution of power in American society, World Politics, 10(1), pp. $123-143$.

Petts, J. (1995) Waste management strategy development: a case study of community involvement and consensus-building in Hampshire, Journal of Environmental Planning and Management, 38(4), pp. 519-536.

Renn, O. (1998) The role of risk communication and public dialogue for improving risk management, Risk Decision and Policy, 3(1), pp. 5-30.

Renn, O., Stegelmann, G., Albrecht, G. \& Kotte, U. (1984) An empirical investigation of citizens' preferences among four energy scenarios, Technological Forecasting and Social Change, 26, pp. 11-46.

Rhodes, R. A. W. (1997) Understanding Governance (Buckingham: Open University Press).

Roe, M. (2000) Landscape planning for sustainability: community participation in Estuary Management Plans, Landscape Research, 25(2), pp. 157-181.

Rydin, Y. \& Pennington, M. (2000) Public participation and local environmental planning: the collective action problem and the potential of social capital, Local Environment, 5(2), pp. 153-169.

Rydin, Y. \& Thornley, A. (2002) An agenda for the new millennium, in: A. Thornley Planning in the UK: Agendas for the New Millennium (Aldershot: Ashgate).

Scott, A. (1999) Whose futures? A comparative study of Local Agenda 21 in mid-Wales, Planning Practice and Research, 14(4), pp. 401-421.

Scottish Natural Heritage (1999) National Parks for Scotland: Scottish Natural Heritage's Advice to Government (Edinburgh: SNH).

Selman, P. (1998) Local Agenda 21: substance or spin? Journal of Environmental Planning and Management, 41(5), pp. 533-553.

Sharp, L. \& Connelly, S. (2001) Theorising participation: pulling down the ladder, in: A. Thornley Planning in the UK: Agendas for the New Millennium (Aldershot: Ashgate).

Shucksmith, M. (2000) Endogenous development-social capital and social inclusion: perspectives from LEADER in the UK, Sociologia Ruralis, 40(2), pp. 208-218.

Shurmer-Smith, P. \& Hannam, K. (1994) Worlds of Desire, Realms of Power: A Cultural Geography (London: Edward Arnold).

Sidaway, R. (1998) Consensus Building. Good Practice in Rural Development No. 5 (Edinburgh: Scottish National Rural Partnership).

Skollerhorn, E. (1998) Habermas and nature: the theory of communicative action for studying environmental policy, Journal of Environmental Planning and Management, 41(5), pp. 555-573.

UNCED (1992) Agenda 21. United Nations Conference on Environment and Development, New York.

Warner, M. \& Jones, P. (1998) Assessing the Need to Manage Conflict in Community-based Natural Resource Projects, Natural Resource Perspectives 35 (London: ODI).

White, S. C. (1996) Depoliticising development: the uses and abuses of participation, Development in Practice, 6(1), pp. 6-15.

Wilcox, D. (1994) The Guide to Effective Participation (Brighton: Partnership Books).

Williams, L. (1995) Resolving planning conflicts, Town and Country Planning, 166(10), pp. $263-265$.

Wilson, A. \& Charlton, K. (1997) Making Partnerships Work: A Practical Guide for the Public, Private, Voluntary and Community Sectors (York: Joseph Rowntree Foundation).

Wragg, A. (2000) Towards sustainable landscape planning: experiences from the Wye Valley AONB, Landscape Planning, 25(2), pp. 183-200.

Young, S. (1996) Promoting Participation and Community-Based Partnerships in the Context of Local Agenda 21: A Report for Practitioners (Manchester: University of Manchester). 